\title{
Comparison between Four Types of Long Term Tube Feeding Regarding Nutritional Effects, Complications and Outcomes
}

\author{
Muneerah Albugami ${ }^{1}$, Yasmin Al Twaijri ${ }^{2}$, Abeer Ibrahim ${ }^{3,}$, , Habib Bassil ${ }^{1}$, Ulrike Laudon ${ }^{1}$, \\ Mohamed El Karouri ${ }^{1}$, Abdulaziz Al Rashed ${ }^{1}$, Abdelazeim Elamin ${ }^{1}$, Ahmed Sabry ${ }^{1}$, \\ Rania Abdelreheem ${ }^{3}$, Abdulwahab Motieb ${ }^{1}$, Ali Al Araj ${ }^{1}$, Reem Hawary ${ }^{4}$, Sawsan Al Balawi ${ }^{4}$ \\ ${ }^{1}$ Internal Medicine Department, King Faisal Specialist Hospital and Research Center, Riyadh, KSA \\ ${ }^{2}$ Research Center, King Faisal Specialist Hospital and Research Center, Riyadh, KSA \\ ${ }^{3}$ Internal Medicine Department, Faculty of Medicine, Alexandria University, Alexandria, Egypt \\ ${ }^{4}$ Nutrition Services, King Faisal Specialist Hospital and Research Center, Riyadh, KSA

\section{Email address:} \\ mbugami@kfshrc.edu.sa (M. albugami), yasmin@kfshrc.edu.sa (Y. A. Twaijri), abeer_i2002@yahoo.com (A. Ibrahim), \\ hbassil@kfshrc.edu.sa (H. Bassil), ulaudon@kfshrc.edu.sa (U. Laudon), melkarori@kfshrc.edu.sa (M. E. Karouri), \\ Abdulaziz.alrashed@medportal.ca (A. A. Rashed), abdelazeim@hotmail.com (A. Elamin), asabri@kfshrc.edu.sa (A. Sabry), \\ rabdelreheem99@kfshrc.edu.sa (R.Abdelreheem),Stronghold222@gmail.com (A. Motieb), al_araj@hotmail.com (A. A. Araj), \\ rhawary@kfshrc.edu.sa (R. Hawary), sbalawi@kfshrc.edu.sa (S. A. Balawi)
}

\section{To cite this article:}

Muneerah Albugami, Yasmin Al Twaijri, Abeer Ibrahim, Habib Bassil, Ulrike Laudon, Mohamed El Karouri, Abdulaziz Al Rashed, Abdelazeim Elamin, Ahmed Sabry, Rania Abdelreheem, Abdulwahab Motieb, Ali Al Araj, Reem Hawary, Sawsan Al Balawi. Comparison between Four Types of Long Term Tube Feeding Regarding Nutritional Effects, Complications and Outcomes. Science Journal of Clinical Medicine. Vol. 4, No. 3, 2015, pp. 60-66. doi: 10.11648/j.sjcm.20150403.12

\begin{abstract}
Objective: to compare four types of long term tube feeding regarding nutritional effects, tube-related complications and outcome. Methods: retrospective study. Results: Mean BMI at time of tube insertion is 23.3, two years later 20.3 ( $\mathrm{P}=0.0312$ ). Patients have follow up with HHC their mean BMI at base line is 23.5 , after two years 21.53 ( $\mathrm{p}=0.547$ ). No difference regarding albumin, urea, sodium, potassium, hemoglobin over 6, 12, 24 months either patient has followed up with HHC or not. High creatinine level in 12 months with jejunostomy tube $(\mathrm{p}=0.0270)$. There are no major complications among the patients. No minor complications within $48 \mathrm{~h}$ of tube insertion in $42.18 \%$, No complications after $48 \mathrm{~h}$ of tube insertion in $36.05 \%$. The mortality rate is $56.59 \%$. Old age is associated with a higher mortality ( $\mathrm{p}$ 0.0018) and survival is better for patients who have HHC follow up ( $\mathrm{p}$ $<0.0001)$. The commonest cause of death is aspiration pneumonia with septic shock and respiratory failure $37.68 \%$ and PFG has the highest mortality rate. Conclusion: 1) Patients on long-term feeding tubes don't gain weight. There is an urgent need to improve method of nutritional assessment and to have regular follow up to calculate their calories requirement and adjust their formula accordingly; 2) The nutritional status in four feeding tubes is similar except in12 months there is significant difference in creatinine in jejunostomy tube; 3) Rate of complications is low among our patients with reference to the long period of follow-up. Almost all complications have been mild and could be managed throughout adequately; 4) Tube related infection and leakage reported more in PFG. It could be because it is the commonest tube used among our patients.
\end{abstract}

Keywords: Enteral Tube Feeding, Mortality, Percutaneous Fluoroscopic Gastrostomy, Gastro Jejunostomy, Complications, Percutaneous Endoscopic Gastrostomy

\section{Introduction}

During the past two decades, enteral nutrition has become increasingly popular because of improved nutritional formulas, advances in catheter technology, and the development of less invasive techniques (including endoscopic and fluoroscopic) for placement of feeding tubes 1 . In western countries the number of patients on home enteral nutrition has doubled ${ }^{2}$. Despite the benefit of the enteral route for maintaining nutrition, complications have been reported .There has been few long terms follow up 
studies. The use of feeding tubes in patients at KFSH\&RC is common. Data about the use of long term feeding tubes in Saudi Arabia is limited ${ }^{3,4,5,6 .}$ The purpose of our study is to compare nasogastric tube (NGT), percutaneous endoscopic gastrostomy (PEG) tube, percutaneous fluoroscopy gastrosubetomy (PFG) tube and jejunostomy (JFT) tube regarding nutritional effects, tube-related complications and outcome. To our knowledge, our study is the first study conducted in Saudi Arabia to study these issues.

\section{Methods}

This is a retrospective study of adult patients on long term feeding tubes admitted to KFSH\&RC from January 2002 to December 2007. Inclusion criteria: 1 - adult patient (age $>14$ years old), 2- patients need long term tube feedings $(>4$ weeks), 3- feedings tube is inserted at KFSH\&RC. Exclusion criteria include patients need feeding tubes for short term for 4 weeks or less because of acute illness e.g. postoperative, ICU patients and patient's terminal illness required palliative care. The study was approved by Office of Research Affair (ORA) at KFSH\&RC.

The medical records of all patients are analyzed using the following parameters: demographic data of the patients (age, sex), indications for feeding tubes, types of feeding tubes NGT, PEG, PFG and JFT. Reasons to keep patients on longterm NGT feeding, types of formula, nutritional effects (hemoglobin, albumin, prealbumin, urea, cretintine, sodium and potassium before and after feeding tubes insertion at baseline, 6 months .12 months and 24 months. BMI was compared at time of tube insertion and two years later. Complications were classified as major and minor. Major complications are defined as there is a need for surgical intervention. Minor complications are divided into early complication within 48 hours of tube insertion such as (diarrhoea, dehydration, abdominal bloating, vomiting and bleeding at sit of insertion) and late complications after 48 hours such as infection at site of insertion, block, malposition, leakage), Reason to change the tube . Aspiration pneumonia is not included in the complications because it was evaluated separately in other study. Outcome: Mortality rate and factors influenced outcomes.

\section{Data Analysis}

All the statistical analysis of data was done by using the software package SAS version 9.3 (Statistical Analysis System, SAS Institute Inc., Cary, NC, USA). Descriptive statistics for the continuous variables are reported as mean \pm standard deviation and categorical variables are summarized as frequencies and percentages. Continuous variables are compared by Student's paired t-test while categorical variables are compared by Chi-square test. Univariate and multivariate logistic regression were used to study the effect of the different risk factors on the frequency of aspiration pneumonia after using the feeding tube and on the patients' outcome. The level of statistical significance is set at $\mathrm{p}<0.05$.

\section{Results}

Numbers of medical records from January 2002 to December 2007 are 389. Patients excluded from the study are 244 because of 227 patients have tube feed inserted for short term which is less than 4 weeks, 7 patients their charts are missing and 10 patients their charts are in KFSH\&RCJeddah and it is very difficult to request them. Patients who met the criteria of study are 145 patients. The main sample characteristics are presented in Table 1, (83 men and 62 women) males are predominant $(57.24 \%)$, with a mean age of $65.3 \pm 23.7,85.03 \%$ are bedridden, $21.38 \%$ have tracheostomy and $37.24 \%$ have follow up with Home health care service(HHC) of the hospital. The commonest indications for enteral feeding tube are cerebrovascular accident (CVA) 49\%, dementia 38.1\%, inadequate oral intake $17.69 \%$. Parkinson's disease in $6.1 \%$ of patients and it is not documented if it is associated with dementia or not. Patients who have two or more indications for feeding tubes are $29 \%$. The commonest feeding tube used is $\mathrm{PFG}$ in $56.55 \%$ of patients as presented in Table 1. Patients who have NGT is $20.69 \%$ because family refused to insert other types of feeding tubes. They don't want to expose patients to any invasive procedures and expect they will get better. The commonest type of formula used is Jevity in $56.46 \%$ of patients.

BMI when tube was inserted for the first time is known in 98 patients $(72.59 \%)$ and BMI two years later are known in 38 alive patients $(27.94 \%)$. The mean of BMI at time of tube insertion is 23.3 and two years later is $20.3(p=0.0312)$. For the patients who have follow up with $\mathrm{HHC}$, their BMI mean at base line is 23.5 and after two years is $21.2(\mathrm{p}=0.547)$. By using general linear model analysis (GLM) there is no difference between the four types of feeding tubes in BMI measurement two years after tube insertion $(p=0.4409)$.

As presented in table 2 there is no difference between the four types of feeding tubes regarding albumin, urea, sodium, potassium and hemoglobin over 6, 12, 24 months either patient has follow up with HHC or not. There is increased in creatinine level in 12 months as compared to baseline in patients who have JFT $(\mathrm{p}=0.0270)$. However this not seen in other parameters likes urea, sodium and potassium. By using general linear model analysis (GLM) in12 months there is significant difference in creatinine level in JFT $(p=0.0011)$. The mean creatinine level in JFT is 376 but in NGT, PEG and PFG $(81.6,97.25,84.74)$ respectively.

There are no major complications found among the patients, only minor complications. There are no complications within $48 \mathrm{~h}$ of tube insertion in 62 patients $(42.18 \%)$. As presented in table 3 , minor complications are diarrhea in 8 patients $(5.44 \%)$, dehydration in 4 patients $(2.72 \%)$, vomiting in 3 patients $(2.04 \%)$, diarrhoea + abdominal bloating in 2 patients $(1.36 \%)$, bleeding at site of insertion in 2 patients $(1.36 \%)$, abdominal bloating in one patient $(0.68 \%)$, high residual in one patient $(0.68 \%)$ and pneumoperitoneumin in one patient $(0.68 \%)$, and it resolved spontaneous without surgical intervention. 
There are no complications after $48 \mathrm{~h}$ of tube insertion in 53 patients $(36.05 \%)$. As presented in table 3, complications reported are infection at site of insertion in 25 patients (17.0\%) and 6 patients $(4.08 \%)$ their tube are changed, tube block in 12 patients $(8.16 \%)$ and 10 patients their tube are changed $(6.85 \%)$, malpositionin in 4 patients $(2.72 \%)$, leakage in 22 patients $(14.97 \%)$ and 13 patients $(8.84 \%)$ their tube are changed. There is no difference between the four tubes regarding the early complications within $48 \mathrm{~h}$ of tube insertion $(\mathrm{p}=0.583)$. However there is a significant difference regarding the complications after $48 \mathrm{~h}$ of tube insertion, the infection at the site of insertion which reported more in PFG $(p=0.0066)$. It could be because it is the commonest tube used among our patients. There is no difference regarding tube block $(p=0.175)$ or malpositionin $(\mathrm{p}=0.8466)$. There is a a significant difference regarding leakage in PFG and PFG $(p=0.0022)$.

Reason to change the tube is routine in70 patient $(47.62 \%)$, there is no difference regarding reason to change the tube between the four tubes $(p=0.2771)$ as in figure 1 . The survival rate is $43.4 \%$ and the mortality rate is $56.6 \%$. Old age is a poor prognostic factor associated with a higher mortality ( $p=0.0018$, odds ratio 1.028) and survival is better for patients who have HHC follow up ( $p<0.0001$, odds ratio 7.329).The commonest cause of death is aspiration pneumonia with septic shock and respiratory failure $37.68 \%$ and PFG has the highest mortality rate and that may be because it is the commonest feeding tube used among our patients as presented in table 4, 5,6.

Table 1. The demographic data of the patients

\begin{tabular}{|c|c|c|}
\hline & frequency & percent \\
\hline male & 83 & $57.24 \%$ \\
\hline female & 62 & $42.76 \%$ \\
\hline \multicolumn{3}{|l|}{ age } \\
\hline$<65$ & 42 & $29.8 \%$ \\
\hline $66-79$ & 63 & $44.7 \%$ \\
\hline$>80$ & 36 & $25.5 \%$ \\
\hline $65.3 \pm 23.7$ & & \\
\hline bedridden & 125 & $85.03 \%$ \\
\hline Tracheostomy when feeding tube inserted & 31 & $21.38 \%$ \\
\hline Diabetic patients & 22 & $14.97 \%$ \\
\hline $\begin{array}{l}\text { Indication for enteral feeding tube inserted } \\
\text { cerebrovascular accident (CVA) }\end{array}$ & 74 & $51 \%$ \\
\hline Dementia & 56 & $38.1 \%$ \\
\hline Inadequate oral intake & 26 & $17.69 \%$ \\
\hline Mental retardation & 15 & $10.20 \%$ \\
\hline Parkinson's disease & 9 & $6.1 \%$ \\
\hline Nasopharyngeal cancer & 4 & $9.8 \%$ \\
\hline Myopathy, sever dysphagia & 2 & $4.88 \%$ \\
\hline Hunter syndrome & 1 & $2.44 \%$ \\
\hline Arnold chiari malformation & 1 & $2.44 \%$ \\
\hline Cerebral palsy & 1 & $2.44 \%$ \\
\hline Multiple systemic atrophy & 1 & $2.44 \%$ \\
\hline Childhood spinal atrophy & 1 & $2.44 \%$ \\
\hline Uterine tumor & 1 & $2.44 \%$ \\
\hline Becker's muscular dystrophy/multiple sclerosis & 1 & $2.44 \%$ \\
\hline Degenerative metabolic & 1 & $2.44 \%$ \\
\hline Tounge cancer & 1 & $2.44 \%$ \\
\hline Pituitary maroadenoma with hydrochelus & 1 & $2.44 \%$ \\
\hline Pituitary adenoma & 1 & $2.44 \%$ \\
\hline Amyotrophic latral sclerosis & 1 & $2.44 \%$ \\
\hline Post brain tumor resection & 1 & $2.44 \%$ \\
\hline Low grade oligodendroglioma & 1 & $2.44 \%$ \\
\hline Woodhouse sakati & 1 & $2.44 \%$ \\
\hline Cancer of tonsil & 1 & $2.44 \%$ \\
\hline Hypopharyngeal squamous cell carcinoma & 1 & $2.44 \%$ \\
\hline Quadriplegia & 1 & $2.44 \%$ \\
\hline Cerebellar degeneration & 1 & $2.44 \%$ \\
\hline Patients have $2>$ indications for enteral feeding tube inserted & 43 & $29.66 \%$ \\
\hline Swallowing assessment test - Positive test & 90 & $62.50 \%$ \\
\hline $\begin{array}{l}\text { Modified barium swallow test - Positive test } \\
\text { types of feeding tubes }\end{array}$ & 81 & $55.10 \%$ \\
\hline NGT & 30 & 20.69 \\
\hline Jejunostomy feeding tubes (JFT) & 13 & 8.97 \\
\hline percutaneous endoscopic gastrostomy (PEG) & 19 & 13.10 \\
\hline percutaneous fluoroscopy gastrostomy ( $\mathrm{PFG}$ ) & 82 & 56.55 \\
\hline Home health care follow up & 54 & $37.24 \%$ \\
\hline - male & 31 & $21.68 \%$ \\
\hline - female & 23 & $16.08 \%$ \\
\hline
\end{tabular}


Complications and Outcomes

Table 2. Difference between the four types of feeding tubes regarding albumin, urea, creatinine, sodium, potassium and hemoglobin

\begin{tabular}{|c|c|c|c|c|c|c|c|}
\hline Duration & $\begin{array}{l}\text { Albumin } \\
<=30 \mathrm{mg} / \mathrm{dl}\end{array}$ & prealbumin & $\begin{array}{l}\text { Urea } \\
2.5-7.5 \mathrm{mmol} / \mathrm{l}\end{array}$ & $\begin{array}{l}\text { Creatinine } \\
46-96 \mu \mathrm{mol} / \mathrm{l}\end{array}$ & $\begin{array}{l}\text { Hemoglobin } \\
11-16 \mathrm{~g} / \mathrm{dl}\end{array}$ & $\begin{array}{l}\text { Sodium } \\
135-147 \mathrm{mmol} / \mathrm{l}\end{array}$ & $\begin{array}{l}\text { Potassium } \\
3.5-5 \mathrm{mmol} / \mathrm{l} \\
\end{array}$ \\
\hline 6 months & $\mathrm{P}=0.4393$ & 00 & $\mathrm{P}=0.1777$ & $\mathrm{P}=0.1634$ & $\mathrm{P}=0.3213$ & $\mathrm{P}=0.9291$ & $\mathrm{P}=0.9989$ \\
\hline 12 months & $\mathrm{P}=0.6458$ & 00 & $\mathrm{P}=0.2862$ & $\mathrm{P}=0.0270$ & $\mathrm{P}=0.2218$ & $\mathrm{P}=0.8020$ & $\mathrm{P}=0.3022$ \\
\hline 24 months & $\mathrm{P}=0.3421$ & 00 & $\mathrm{P}=0.6889$ & $\mathrm{P}=0.5207$ & $\mathrm{P}=0.3333$ & $\mathrm{P}=0.3329$ & $\mathrm{P}=0.2193$ \\
\hline
\end{tabular}

Table 3. Complications of feeding tube

\begin{tabular}{|c|c|c|}
\hline Complications & Frequency & $\%$ \\
\hline \multicolumn{3}{|l|}{ Early (48 h) } \\
\hline No complications & 62 & $42.18 \%$ \\
\hline Diarrhoea & 8 & $5.44 \%$ \\
\hline Dehydration & 4 & $2.72 \%$ \\
\hline Abdominal bloating & 1 & $0.68 \%$ \\
\hline High residual & 1 & $0.68 \%$ \\
\hline Vomiting & 3 & $2.04 \%$ \\
\hline Diarrhoea + Abdominal bloating & 2 & $1.36 \%$ \\
\hline Pneumo peritoneum & 1 & $0.68 \%$ \\
\hline Bleeding at sit of insertion & 2 & $1.36 \%$ \\
\hline Unknown & 61 & $41.50 \%$ \\
\hline \multicolumn{3}{|l|}{ Late after $48 \mathrm{~h}$} \\
\hline No complications & 53 & $36.05 \%$ \\
\hline infection at site of insertion & 25 & $17.0 \%$ \\
\hline Block & 12 & $8.16 \%$ \\
\hline Malposition & 4 & $2.72 \%$ \\
\hline Leakage & 22 & $14.97 \%$ \\
\hline Unknown & 33 & $22.45 \%$ \\
\hline
\end{tabular}

Table 4. Outcome

\begin{tabular}{|c|c|c|c|c|c|}
\hline \multirow[b]{2}{*}{ Total } & \multicolumn{2}{|c|}{ alive } & \multicolumn{2}{|c|}{ died } & \multirow[t]{2}{*}{ P value } \\
\hline & 56 & $43.4 \%$ & 73 & $56.59 \%$ & \\
\hline \multicolumn{6}{|l|}{ Gender } \\
\hline Male & 28 & $22.1 \%$ & 44 & $30.56 \%$ & \multirow{2}{*}{0.1764} \\
\hline Female & 28 & $22.1 \%$ & 27 & $18.75 \%$ & \\
\hline \multicolumn{6}{|l|}{ age group } \\
\hline$<65$ & 23 & $16.43 \%$ & 14 & $10 \%$ & \multirow{3}{*}{0.0195} \\
\hline $66-79$ & 24 & $17.14 \%$ & 33 & $23.57 \%$ & \\
\hline$>80$ & 7 & $5 \%$ & 24 & $17.14 \%$ & \\
\hline follow up with Home health care & 36 & $25 \%$ & 14 & $9.72 \%$ & \multirow{2}{*}{0.0001} \\
\hline no follow up with Home health care & 20 & $13.89 \%$ & 57 & $39.58 \%$ & \\
\hline
\end{tabular}

Table 5. Cause of death and long term feeding tubes

\begin{tabular}{|c|c|c|c|c|c|}
\hline Cause of death & JFT & NGT & PEG & PFG & total \\
\hline Acute renal failure & 0 & 0 & 0 & 1 & $1(1.52 \%)$ \\
\hline Heart failure & 0 & 0 & 0 & 1 & $1(1.52 \%)$ \\
\hline malignancy & 0 & 3 & 1 & 3 & $7(10.61 \%)$ \\
\hline Septic shock & 3 & 3 & 4 & 10 & $20(30.30 \%)$ \\
\hline Septic shock + Acute renal failure & 0 & 0 & 0 & 1 & $1(1.52 \%)$ \\
\hline Septic shock + gastrointestinal bleeding & 0 & 0 & 0 & 2 & $2(3.03 \%)$ \\
\hline $\begin{array}{l}\text { Septic shock + Acute respiratory failure/acute respiratory } \\
\text { distress syndrome }+ \text { Aspiration pneumonia }\end{array}$ & 1 & 6 & 2 & 16 & $25(37.88 \%)$ \\
\hline Total & $\begin{array}{l}4 \\
6.06 \%\end{array}$ & $\begin{array}{l}14 \\
21.21 \%\end{array}$ & $\begin{array}{l}8 \\
12.12 \%\end{array}$ & $\begin{array}{l}40 \\
60.61 \%\end{array}$ & \\
\hline Unknown & 0 & 2 & 1 & 6 & $9(13.64 \%)$ \\
\hline
\end{tabular}


Table 6. Prognostic factors affecting outcome

\begin{tabular}{lll}
\hline & P value & odds ratio \\
\hline Age & 0.0018 & 0.028 \\
Gender & 0.1776 & 0.614 \\
Dementia & 0.8254 & 1.085 \\
Have 2 or more indications for feeding tubes & 0.5582 & 0.797 \\
HHC follow up & $<0.0001$ & 7.329 \\
Albumin 6 months & 0.5595 & 1.038 \\
Albumin 12 months & 0.1145 & 0.916 \\
Creatinine 6 months & 0.6286 & 0.999 \\
Creatinine 12 months & 0.5252 & 1.003 \\
Urea 6 months & 0.2978 & 1.035 \\
Urea 12 months & 0.9339 & 1.005 \\
Sodium 6 months & 0.3092 & 0.953 \\
Sodium 12 months & 0.4813 & 1.032 \\
Potassium 6 months & 0.5114 & 0.790 \\
Potassium 12 months & 0.7288 & 1.222 \\
Haemoglobin 6 months & 0.7691 & 1.00 \\
Haemoglobin 12 months & 0.4754 & 0.992 \\
\hline
\end{tabular}

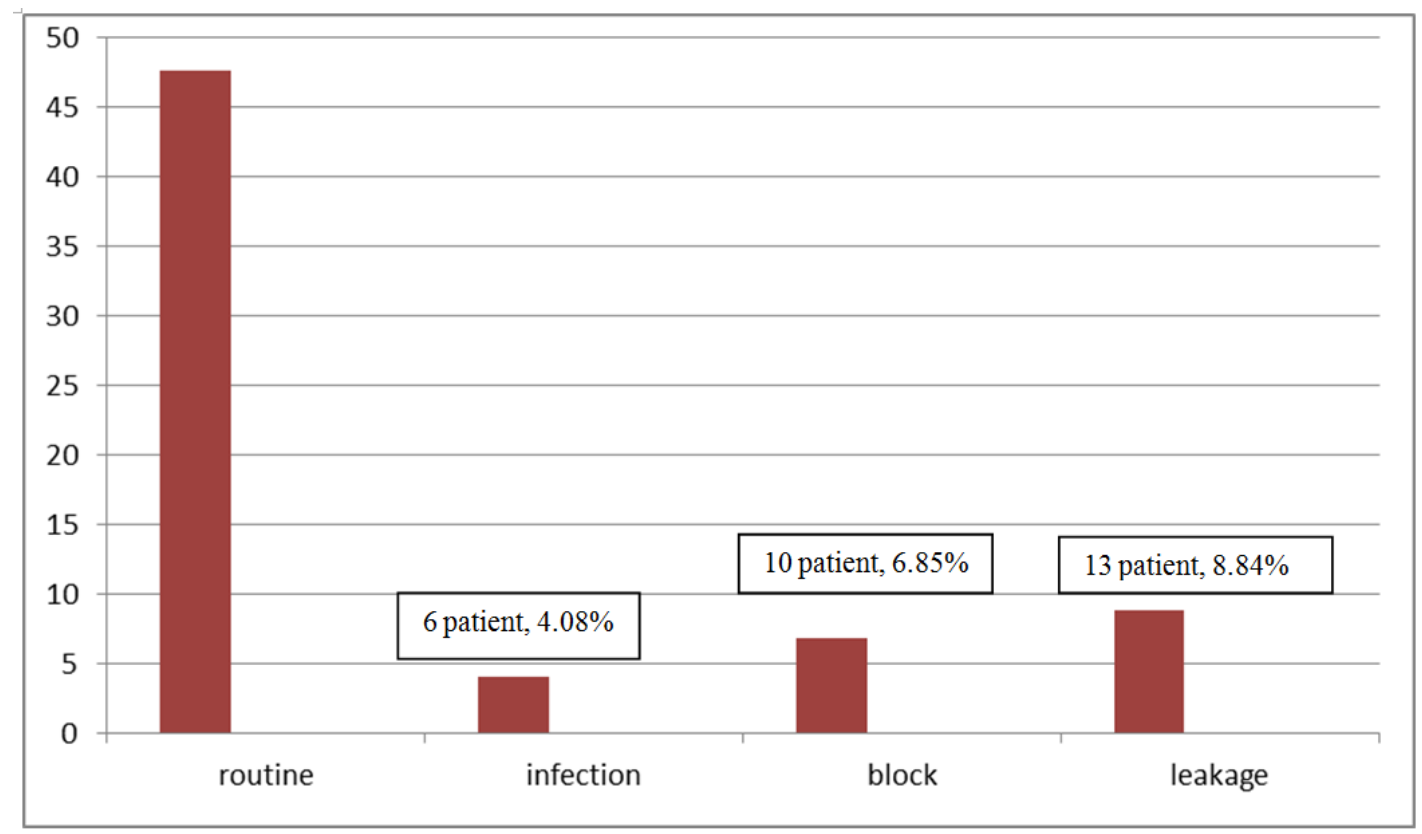

Figure 1. Reason to change the tube

\section{Discussion}

There is a failure to gain weight after tube insertion; actually there is evidence of loss weight. This could be because of inadequate nutritional support and the patients are not taking enough caloric requirements; there is no follow up from a dietarian for nutritional assessment. These patients continue to have the same amount of feeding formula without any adjustment. Or it may be as a result of multiple comorbidities in elderly patients which may affect their nutritional status.

Either a patient has follow up with $\mathrm{HHC}$ or not, the nutritional status in four feeding tubes is similar in 6 months, 12 months and 24 months. There is an increase in creatinine level in 12 months as compared to baseline in patients who have JFT. This could be related to inadequate fluid intake during feeding which cause dehydration or may occur as a result of multiple comorbidities among elderly which may affect the renal function in addition to medications like diuretic. JFT is uncommon to be used among our patients. We don't know the baseline creatinine in patients who have JFT which could be already high and not related to JFT insertion.

Prealbumin has never been recorded in any patients. It is clear that prealbumin is not used in our clinical practice to assess the nutritional status of the patients.

In literature review PEG is more effective than NGT in improving the nutritional status. ${ }^{3,4,5}$ A study showed that the usage of PEG cause stabilization of weight and an increase in serum albumin within two months of beginning PEG tube feedings ${ }^{7}$. Another study showed that within six months $50 \%$ of the patients had gained weight, while $31 \%$ had no change in their weight ${ }^{8}$ 
Despite the attractiveness of the enteral route for maintaining nutrition, complications have been reported. There are no major complications found among our patients, only minor complications. Major complications are gastric perforation, gastrocolic fistula, internal leakage, dehiscence, peritonitis, aspiration pneumonia, subcutaneous abscess and buried bumper syndrome (migration of the internal bumper of the PEG tube into the gastric or abdominal wall) Minor 9,10,11 complications are blockages, dislodgements, degradation, external leakage, and unplanned removal and site infection There are no complications within $48 \mathrm{~h}$ of tube insertion and all complications reported are minors. Rate of complications related to feeding tube is low among our patients. While the literature reports minor complications for PEGs range from $0 \%$ to $27.1 \%$ and ranging from $23 \%$ to $46 \%$ for PFGs, the methods of reporting complication rates were inconsistent $^{13}$. There is a study which showed that pneumoperitoneum on routine imaging is not unexpected and slowly resolves over 1-3 days ${ }^{14}$. Pneumoperitoneum was a common finding after PGJ tube placement. Conservative management of pneumoperitoneum after PGJ is warranted ${ }^{15}$. There is a study which showed that deep stomal infection is more frequent in PEG than in PFG because tube is passed through the mouth/oropharynx and can be contaminated by oral flora, resulting in wound infection. Prophylactic antibiotics is needed in PEG, however, prophylactic antibiotics is not a routine practice for PFG. Complications have been reported in $2 \%-12 \%$ of patients in whom jejunostomy tubes were placed. $1,16.20$

In our patients the most significant prognostic factors are age and HHC .Old age is a poor prognostic factor associated with a higher mortality and survival is better for patients who have HHC follow up. The commonest cause of death is aspiration pneumonia with septic shock and respiratory failure and PFG has the highest mortality rate and that may be because it is the commonest feeding tube used among our patients.

In conclusion, this study has some limitations. It is a retrospective chart review where some missing data are expected and poor documentation was noticed during medical records data collections. Since this study was performed at tertiary care hospital, generalizability may be limited due to the small sample size. However, the diversity of the patients sample should help to reduce the potential effects of that limitation.

Due to the retrospective nature of the study, we could collect only basic clinical information but functional status, quality of life and the patients' cognitive status at the time of tube insertion are not included in our data because they have never been documented in patient charts. Despite these limitations; this is the first study in Saudi Arabia to compare feeding tubes regarding nutritional effects, complications and outcomes. There is an urgent need to improve method of nutritional assessment and to have regular follow up for patients on long term feeding tubes. Rate of complications related to feeding tube is low among our patients (majority are elderly) with reference to the long period of follow-up.
Almost all complications have been mild and could be managed throughout adequately. Further studies should include longer follow up periods, more patients and additional questions regarding quality of life.

\section{References}

[1] Carucci LR, Evaluation of patients with jejunostomy tubes: imaging findings. Radiology. 2002 Apr;223(1):2417.

[2] Simon EJ Janes,. Percutaneous endoscopic gastrostomy: 30day mortality trends and risk factors. Year: 2005, Volume: 51, Issue: 1, Page: 23-29

[3] Salem M. Bazarah, PERCUTANEOUS GASTROSTOMY AND GASTROJEJUNOSTOMY: RADIOLOGICAL AND ENDOSCOPIC APPROACH. Annals of Saudi Medicine, Vol 22, Nos $1-2,2002$

[4] Arabi Y, Haddad S, The impact of implementing an enteral tube feeding protocol on caloric and protein delivery in intensive care unit patients. Nutr Clin Pract. 2004 Oct;19(5):523-30

[5] Hanaa Banjar. Gastrostomy Tube Feeding of Cystic Fibrosis Patients. Bahrain Medical Bulletin, Vol. 26, No. 4, March 2004

[6] Al Rawas M. Percutaneous Fluoroscopic Guided Gastrostomy 6-Years' Experience in Jeddah,Saudi Arabia. Qatar Medical Journal, Volume 9, No. 2, Dec 2000, P55-57

[7] Park RH, Allison MC, Lang J, et al. Randomised comparison of percutaneous endoscopic gastrostomy and nasogastric tube feeding in patients with persisting neurological dysphagia. BMJ 1992;304:1406-9.

[8] Magne N, Marcy PY, Foa C, et al. Comparison between nasogastric tube feeding and percutaneous fluoroscopic gastrostomy in advanced head and neck cancer patients. Eur Arch Otorhinolaryngol. 2001;258:89-92.

[9] Baeten C, Hoefnagels J. Feeding via nasogastric tube or percutaneous endoscopic gastrostomy: a comparison. Scand J Gastroenterol Suppl. 1992;41:189.

[10] McClave, Enteral tube feeding in the intensive care unit: Factors impeding adequate delivery.Crit Care Med 1999; 27:1252-1256

[11] Ciocon JO, Silverstone FA, Graver LM, Foley CJ. Tube feedings in elderly patients. Indications, benefits, and complications. Arch Intern Med 1988; 148:429.

[12] Kaw M, Sekas G. Long-term follow-up of consequences of percutaneous endoscopic gastrostomy (PEG) tubes in nursing home patients. Dig Dis Sci 1994; 39:738.

[13] Dwolatzky T, Berezovski S, Friedmann R, Paz J .A prospective comparison of the use of nasogastric and percutaneous endoscopic gastrostomy tubes for long-term enteral feeding in older people.,Department of Geriatric Medicine, Shaare Zedek Medical Center, Jesuralem, Israel. Clin Nutr. 2001 Dec;20(6):535-40.

[14] Dwyer KM, Watts DD, Thurber JS, et al; Percutaneous endoscopic gastrostomy: the preferred method of elective feeding tube placement in trauma patients. J Trauma. 2002 Jan;52(1):26-32 
[15] Beaver ME Percutaneous fluoroscopic gastrostomy tube placement in patients with head and neck cancer. Arch Otolaryngol Head Neck Surg. 1998 Oct;124(10):1141-4

[16] Dwyer KM, Watts DD, Thurber JS, et al; Percutaneous endoscopic gastrostomy: the preferred method of elective feeding tube placement in trauma patients. J Trauma. 2002 Jan;52(1):26-32.

[17] Galaski A, Gastrostomy tube placement by radiological versus endoscopic methods in an acute care setting: A retrospective review of frequency, indications, complications and outcomes. Can J Gastroenterol. 2009 Feb;23(2):109-14.
[18] Ji Hoon Shin. Updates on Percutaneous Radiologic Gastrostomy/Gastrojejunostomy and Jejunostomy. Gut Liver. 2010 September; 4(Suppl. 1): S25-S31.

[19] Stoneham G, Pneumoperitoneum post-fluoroscopic percutaneous gastrojejunostomy insertion: computed tomography and clinical evaluation. Can Assoc Radiol J. 2012 Aug; 63(3 Suppl):S33-6.

[20] Finucane TE. Tube feeding in dementia: how incentives undermine health care quality and patient safety. J Am Med Dir Assoc. 2007 May;8(4):205-8. Epub 2007 Apr 18. 